\title{
Hidrogel, calagem e adubação no desenvolvimento inicial, sobrevivência e composição nutricional de plantas híbridas de eucalipto
}

\author{
Edinéia Messias Martins Bartieres ${ }^{1 *}$, Natália Hilgert de Souza Carnevali ${ }^{1}$, Elizeu de Souza Lima ${ }^{2}$, Thiago Oliveira Carnevali ${ }^{3}$, \\ Viviane Mallmann ${ }^{4}$ \\ ${ }_{1}^{1}$ Universidade Estadual de Mato Grosso do Sul, BR 163, Km 20, CEP 79980-000, Mundo Novo, MS, Brasil \\ ${ }^{2}$ Universidade Estadual de Campinas, Av. Cândido Rondon, 501, Cidade Universitária, CEP 13083-875, Campinas, SP, Brasil \\ ${ }^{3}$ Universidade Federal da Grande Dourados, Rodovia Dourados-Itahum, Km 12, Cidade Universitária de Dourados, s/nº, CEP 79804-970, Dourados, MS, Brasil \\ ${ }^{4}$ Universidade Estadual de Mato Grosso do Sul, Rua Emílio Mascoli 271, CEP 79985-000, Naviraí, MS, Brasil
}

*Autor correspondente:

estudanteacinatob8305@hotmail.com

Termos para indexação:

Crescimento

Avaliação nutricional

Gel hidroretentor

Index terms:

Initial growth

Nutritional evaluation

Hidroretentor gel

Histórico do artigo:

Recebido em 27/07/2015

Aprovado em 20/04/2016

Publicado em 30/06/2016

doi: 10.4336/2016.pfb.36.86.990
Resumo - Com a premissa de que a utilização de hidrogel associado à calagem e adubação em plantios de eucalipto aumenta a retenção de água e o teor de nutrientes no solo, objetivou-se avaliar a sobrevivência e o desenvolvimento inicial de clones híbridos de Eucalyptus grandis x Eucalyptus camaldulensis, em função da utilização de hidrogel, calagem e adubação. Em um Argissolo Vermelho, foram dispostos os tratamentos: 1) controle, 2) hidrogel, 3) adubação convencional, 4) adubação + calagem, 5) adubação + hidrogel e 6) adubação + calagem + hidrogel. Foi utilizado o delineamento em blocos casualizados, com seis repetições e seis plantas por parcela. Avaliou-se a sobrevivência, a altura, o diâmetro do caule, o teor de macronutrientes na parte aérea e atributos químicos do solo. O tratamento adubação + hidrogel proporcionou maior altura e diâmetro aos 240 dias após o transplante. Contudo, a sobrevivência foi maior no tratamento com adubação convencional. Os resultados indicam a viabilidade do uso de hidrogel. Porém, mais estudos devem ser realizados para comprovação de seus efeitos e recomendação de dosagens adequadas.

\section{Hydrogel, liming and fertilizing in early development, survival and nutritional composition of eucalyptus hybrid plants}

\begin{abstract}
With the premise that use of hydrogel associated with liming and fertilization in eucalyptus plantations increases water retention and nutrient content in the soil, this work aimed to evaluate the survival and early development of the hybrid Eucalyptus grandis x Eucalyptus camaldulensis when using hydrogel, liming and fertilization. In Ultisol, the treatments were: 1) control, 2) hydrogel, 3) conventional fertilization, 4) fertilizer + lime, 5) fertilizer + hydrogel and 6) fertilizer + lime + hydrogel. The treatments were arranged in a randomized block design, with six replications and six plants per plot. We evaluated height, diameter, survival, macronutrient content in shoot and soil chemical properties. The hydrogel + fertilization treatment provided bigger height and diameter at 240 days after transplant, however, the survival was higher in fertilization treatment. The results indicate the viability of the hydrogel use. However but more studies are needed to prove its effects and recommendation of appropriate dosages.
\end{abstract}




\section{Introdução}

O Brasil é um dos maiores produtores de florestas plantadas do mundo, atingindo área aproximada de 7,6 milhões de ha ao final de 2013 (Anuário..., 2013). Ainda segundo a mesma publicação, 68\% dessa área são cultivados pela indústria de papel e celulose, sendo as florestas de eucalipto as mais representativas (72\%), seguidas por pinus $(20,7 \%)$ e demais espécies cultivadas $(7,3 \%)$.

Os solos brasileiros são, em sua maioria, antigos e altamente intemperizados, ácidos e com baixa disponibilidade de nutrientes, especialmente os do Cerrado, o que torna necessária a correção e adubação para níveis adequados ao desenvolvimento das plantas (Souza et al., 2014). Nesse ecossistema, o desenvolvimento das raízes é abreviado pelo excesso de alumínio trocável e também pela deficiência de cálcio, limitando a absorção de água e nutrientes e, consequentemente, a redução da produtividade da madeira do eucalipto (Costa et al., 2014).

A prática de adubação é um fator indispensável para produção de florestas de eucalipto, que mostram alta demanda por nutrientes, especialmente de $\mathrm{N}$, até a formação da copa (Vezzani et al., 2001). Estes mesmos pesquisadores verificaram que, aos 45 meses após plantio ,a quantidade de $\mathrm{N}$ acumulado nas folhas de Eucalyptus saligna era equivalente a $131 \mathrm{~kg} \mathrm{ha}^{-1}$, garantindo, assim, melhor desenvolvimento da planta e maior produtividade de madeira.

Para Bernardi et al. (2012), a eficiência das adubações depende basicamente das doses e fontes dos adubos utilizados, da capacidade de troca catiônica do solo, das características físicas do solo e também da adição de polímeros hidrorretentores (hidrogéis).

Em regiões de clima mais seco e com predominância de solos arenosos, a utilização dos hidrogéis tem trazido resultados satisfatórios, especialmente na cultura do eucalipto. Lopes et al. (2010) verificaram que, com o uso de hidrogel, mudas clonais de E. urograndis apresentaram redução nos sintomas de estresse hídrico, com 37 dias sem irrigação adicional.

Além de seu papel na retenção de água no solo, tem-se verificado que os hidrogéis têm capacidade de redução da lixiviação de nutrientes, devido à sua elevada capacidade de troca catiônica. Bernardi et al. (2012) testaram a associação de hidrogel e adubação na produção de mudas de Corymbia citriodora e verificaram redução de $20 \%$ da adubação rotineira quando associada ao hidrogel, bem como efeito positivo para altura, diâmetro do caule e razão altura da parte aérea/diâmetro do caule.

Com intuito de entender a eficiência do hidrogel no solo e seu papel como auxiliar da nutrição mineral do eucalipto, objetivou-se avaliar a sobrevivência, o crescimento inicial e os teores de nutrientes em Eucalyptus grandis x Eucalyptus camaldulensis, bem como os atributos químicos do solo em função da utilização de hidrogel, calagem e adubação.

\section{Material e métodos}

O estudo foi desenvolvido no Município de Iguatemi, MS, no período de outubro/2013 a junho/2014, na fazenda Santa Maria (“2331'44.85”S e 5432'53.35”W). Anteriormente ao plantio, a área estava sendo utilizada como pastagem para pecuária extensiva, com a forrageira Brachiaria descumbens. O clima da região é do tipo Cwa mesotérmico úmido, segundo a classificação de Köppen (Köppen, 1948). A precipitação média anual é de $1.500 \mathrm{~mm}$ e a temperatura média de $22{ }^{\circ} \mathrm{C}$. Os dados de temperatura e pluviosidade médias para região sul do estado de Mato Grosso do Sul, na época de desenvolvimento do estudo, encontram-se na figura 1.

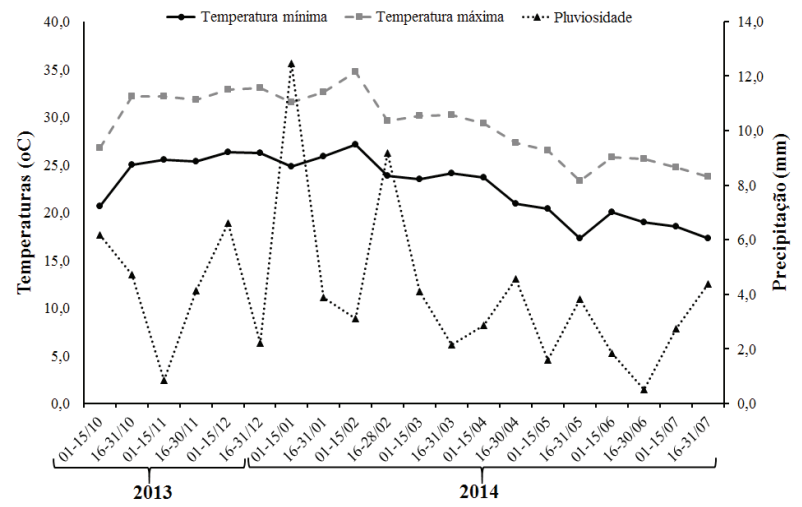

Figura 1. Médias quinzenais de temperaturas mínima e máxima $\left({ }^{\circ} \mathrm{C}\right)$ e precipitação $(\mathrm{mm})$, na época de desenvolvimento do estudo. Iguatemi, MS, 2014.

Fonte: Embrapa Agropecuária Oeste.

O solo no qual foi instalado o estudo está classificado como Argissolo Vermelho de textura arenosa (Santos et al., 2013). Amostras deformadas foram coletadas, com auxílio de trado de rosca, em profundidade de $0-20 \mathrm{~cm}$, para caracterização química (Tabela 1). Avaliou-se: $\mathrm{pH}$ em $\mathrm{CaCl}_{2}$; $\mathrm{P}$ e K, extraídos com solução de Mehlich 1; $\mathrm{Ca}, \mathrm{Mg}$, e Al, extraídos com $\mathrm{KCl}\left(1,0 \mathrm{~mol} \mathrm{~L}^{-1}\right) ; \mathrm{H}+\mathrm{Al}$; soma de bases (SB); capacidade de troca de cátions (CTC) e saturação por bases (V), seguindo a metodologia de Raij et al. (2001). 
Tabela 1. Caracterização inicial dos atributos químicos do solo da área experimental, Iguatemi, MS, 2014.

\begin{tabular}{|c|c|c|c|c|c|c|c|c|c|c|}
\hline MO & pH & $\begin{array}{c}\mathbf{P} \\
\text { (resina) }\end{array}$ & $\mathbf{K}^{+}$ & $\mathrm{Ca}^{2+}$ & $\mathbf{M g}^{2+}$ & $\mathbf{H}^{+}+\mathbf{A} \mathbf{l}^{3+}$ & $\mathbf{A l}^{3+}$ & SB & CTC & $\mathbf{V}$ \\
\hline $\mathrm{g} \mathrm{dm}^{-3}$ & $\mathrm{CaCl}_{2}$ & $\mathrm{mg} \mathrm{dm}{ }^{-3}$ & & & & $\mathrm{cmol}_{\mathrm{c}} \mathrm{dm}^{-3}$ & & & & $\%$ \\
\hline 7,98 & 4,30 & 2,73 & 0,04 & 0,14 & 0,16 & 3,18 & 0,24 & 0,34 & 3,52 & 9,66 \\
\hline
\end{tabular}

$\mathrm{MO}, \mathrm{pH}, \mathrm{H}^{+}+\mathrm{Al}^{3+}$, SB, CTC e V são, respectivamente, matéria orgânica, potencial hidrogeniônico, acidez potencial, soma de bases, capacidade de troca catiônica e índice de saturação por bases.

O clone 1277 do híbrido Eucalyptus grandis $\mathrm{x}$ Eucalyptus camaldulensis foi estudado de acordo com os seguintes tratamentos: 1) controle; 2) hidrogel; 3) adubação convencional; 4) adubação convencional + calagem; 5) adubação convencional + hidrogel; e 6) adubação convencional + calagem + hidrogel. Utilizouse delineamento experimental em blocos casualizados, com seis repetições. A unidade experimental foi composta por 6 plantas, com espaçamento de $3 \mathrm{~m}$ entre plantas e $6 \mathrm{~m}$ entre linhas, com cada linha constituindo um bloco.

Antes do transplante, foi realizada gradagem na área, que antecedeu o coveamento manual de $30 \times 30 \times 30$ $\mathrm{cm}$. O solo retirado de cada cova recebeu seu respectivo tratamento, sendo incorporado manualmente. Ao longo do experimento, os tratos culturais consistiram de capinas e coroamento das plantas, a fim de minimizar a competição com plantas invasoras.

Para composição dos tratamentos com hidrogel, utilizou-se $4 \mathrm{~g} \mathrm{~L}^{-1}$ do polímero Forth $\mathrm{Gel}^{\circledR}$ em pó, sendo aplicado $500 \mathrm{~mL} \mathrm{cova}^{-1}$, seguindo as recomendações do fabricante. Para as covas que receberam calagem, foi adicionada uma quantidade de calcário dolomítico (PRNT de 85\%) capaz de elevar a saturação por bases a 50\%, 30 dias antes do plantio. O cálculo de adubação foi baseado na recomendação de Gonçalves (1995), para o cultivo do eucalipto. A adubação nitrogenada (via ureia) e a potássica (via $\mathrm{KCl}$ ) foram parceladas em duas aplicações, sendo a primeira no plantio $\left(0,4\right.$ g ureia cova ${ }^{-1}$ e $\left.0,054 \mathrm{~g} \mathrm{KCl} \mathrm{cova}^{-1}\right)$ e a segunda trinta dias após o plantio $\left(0,8 \mathrm{~g}\right.$ ureia $\operatorname{cova}^{-1} \mathrm{e}$ $\left.0,054 \mathrm{~g} \mathrm{KCl} \mathrm{cova}^{-1}\right)$. O fósforo foi fornecido via superfosfato triplo (1,93 $\left.\mathrm{g} \mathrm{cova}^{-1}\right)$ no dia do plantio.

Mensalmente, a partir de outubro de 2013 até junho de 2014, foram realizadas aferições de altura das plantas (cm), com auxílio de fita métrica, e diâmetro de caule $(\mathrm{mm}), \mathrm{a} \pm 10 \mathrm{~cm}$ do solo, utilizando-se paquímetro digital. Aos 240 dias após o transplante (DAT), foi avaliada a sobrevivência das plantas, pela contagem dos indivíduos. Foram coletados ramos com folhas, do terço médio, para determinação dos teores de macronutrientes, seguindo a metodologia proposta por Malavolta et al. (1997). A amostragem do solo foi feita em todas as parcelas, com auxílio de trado de rosca, coletando-se duas amostras por cova, analisadas de acordo com a metodologia proposta por Raij et al. (2011).

Os dados foram submetidos à análise de variância e para os fatores significativos foram realizadas análises de regressão, em função das épocas de avaliação. Para análise dos dados de sobrevivência das plantas utilizouse teste Tukey. Para todas as análises realizadas utilizouse até $5 \%$ de probabilidade.

\section{Resultados e discussão}

Em todos os tratamentos, com exceção do controle, a sobrevivência do eucalipto foi considerada satisfatória, uma vez que a mortalidade de plantas não ultrapassou $10 \%$ ao final da amostragem, evidenciando bom estabelecimento do material genético em campo (Figura 2).

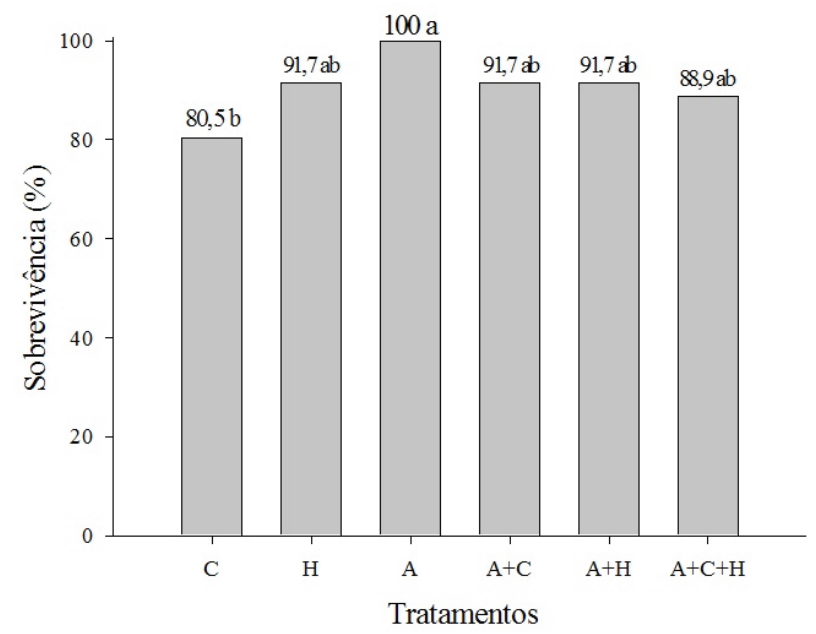

Figura 2. Sobrevivência do eucalipto em função dos diferentes tratamentos, aos 240 dias após transplante. Iguatemi, MS, 2014. $\mathrm{C}=$ controle; $\mathrm{H}=$ hidrogel; $\mathrm{A}=$ adubação; $\mathrm{A}+\mathrm{C}=$ adubação + calagem; $\mathrm{A}+\mathrm{H}=$ adubação + hidrogel e $\mathrm{A}+\mathrm{C}+\mathrm{H}=$ adubação + calagem + hidrogel. Médias seguidas de mesma letra não diferem entre si pelo teste Tukey a $5 \%$. 
Fatores como boa procedência e qualidade das mudas e adequada precipitação pluviométrica foram determinantes na sobrevivência das mudas em campo. Nos primeiros quinze dias após o transplante houve boa regularidade de chuvas (Figura 1), com registros de até $26 \mathrm{~mm}$ em um único dia, incluindo os dias que antecederam o transplante (dados não apresentados), contribuindo, assim, para alta sobrevivência das plantas.

Utilizando apenas adubação de plantio (60 g de superfosfato triplo), Souza et al. (2004) constataram altos valores de sobrevivência, que variou de 92 a 100\%, em cinco clones híbridos de E. grandis x E. urophylla (E. urograndis) com 4 anos de idade. Tonini et al. (2006) também observaram alta sobrevivência (92\%) de clones de E. urograndis aos seis anos, comprovando boa procedência das plantas.

A altura e o diâmetro do caule foram influenciados pela interação entre os tratamentos e a época de avaliação. Aos 240 DAT, o tratamento hidrogel + adubação promoveu maior altura $(123,3 \mathrm{~cm})$, equivalente a um ganho de $11,4 \%$ em relação ao tratamento controle (Figura 3).

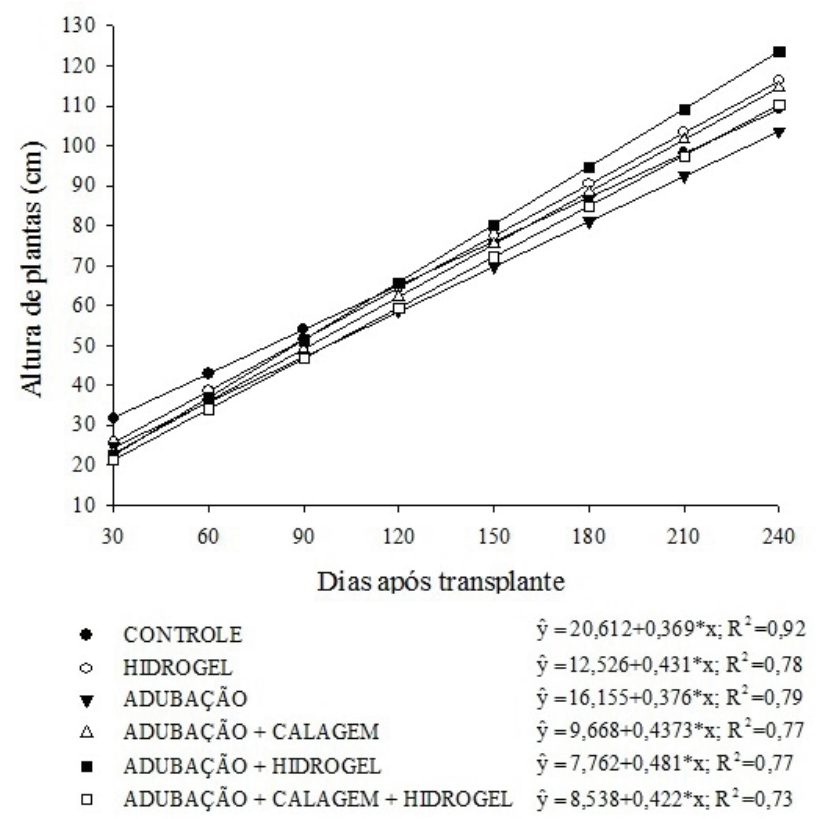

Figura 3. Altura $(\mathrm{cm})$ do eucalipto ao longo do cultivo em função do uso de hidrogel, calagem e adubação. Iguatemi, MS, 2014.

A associação do hidrogel + adubação também aumentou significativamente o diâmetro do caule, que alcançou valor máximo de 123,2 $\mathrm{mm}$ aos 240 DAT (Figura 4), o que equivale a um aumento de $18 \%$ em relação ao tratamento controle. O benefício do hidrogel possivelmente está associado ao efeito na retenção do fertilizante, liberando-o gradualmente, assim como observado por Bernardi et al. (2012). Ao associar hidrogel (6 $\left.\mathrm{g} \mathrm{L}^{-1}\right)$ e adubação com NPK (19-6-10), esses autores verificaram um aumento de $22,9 \%$ em altura e 23,1\% no diâmetro do caule de mudas de Corymbia citriodora, comparado ao uso isolado da adubação. Ao final do experimento, constataram que o uso do hidrogel representou uma economia de pelo menos $20 \%$ da adubação rotineira utilizada em viveiro comercial.

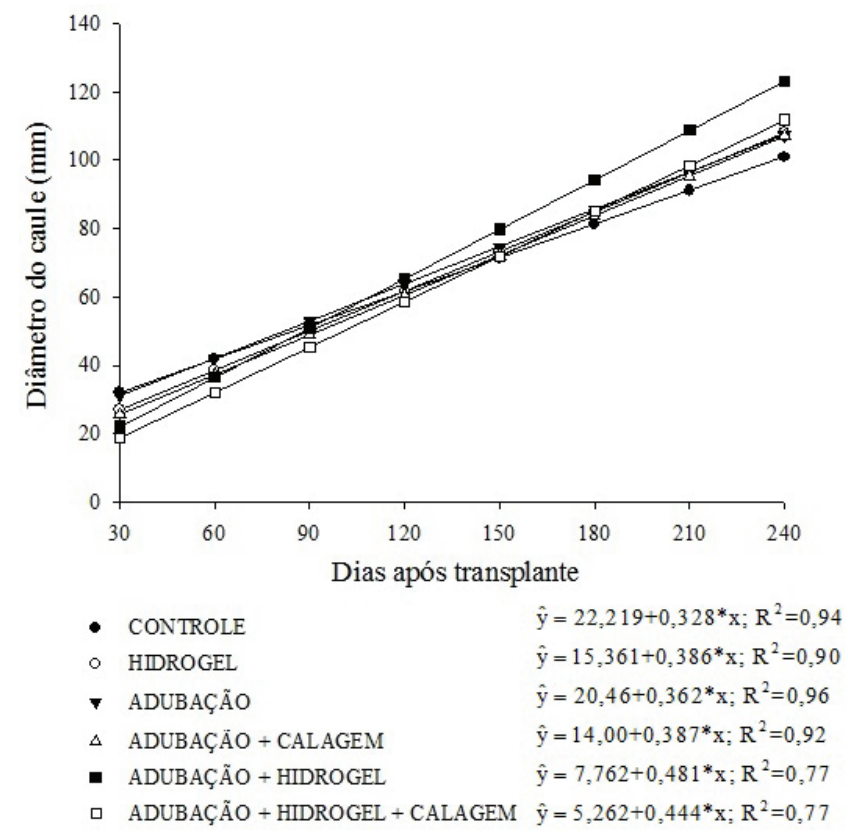

Figura 4. Diâmetro de caule (mm) do eucalipto ao longo do cultivo em função do uso de hidrogel, calagem e adubação. Iguatemi, MS, 2014.

Para os teores de macronutrientes na parte aérea das plantas, observou-se diferença somente para $\mathrm{P}$ e $\mathrm{K}$ (Tabela 2). Os valores médios de NPK obtidos no tecido vegetal são muito maiores do que aqueles recomendados por Gonçalves et al. (1995), que são de $13,5 \mathrm{a} 18 \mathrm{~g} \mathrm{~kg}^{-1}$ de N, 0,9 a 1,3 $\mathrm{g} \mathrm{kg}^{-1}$ de P e 9,0 a $13 \mathrm{~g} \mathrm{~kg}^{-1}$ de K, para a cultura do eucalipto.

$\mathrm{O}$ teor de $\mathrm{P}$ foi maior nos tratamentos adubação + calagem, seguido de adubação + calagem + hidrogel e adubação + hidrogel, não sendo observada diferença significativa entre eles. Devido ao fósforo ser um nutriente fortemente adsorvido aos óxidos de ferro e alumínio (Souza et al., 2014), a utilização da calagem pode ser muito benéfica, pois além de elevar os teores de $\mathrm{Ca}$ e $\mathrm{Mg}$ e reduzir os teores solúveis de $\mathrm{Fe}$ e $\mathrm{Al}$ do solo, também aumenta a concentração de P lábil na solução do solo, tornando-o disponível para as plantas (Silva et al., 2007). 
Tabela 2. Teores de macronutrientes na parte aérea do eucalipto, aos 240 dias após o transplante, em função de diferentes tratamentos. Iguatemi, MS, 2014.

\begin{tabular}{cccccrrrr}
\hline \multirow{2}{*}{$\begin{array}{c}\text { Nutrientes } \\
(\mathbf{g} \text { kg }\end{array}$} & Controle & Hidrogel & Adubação & $\begin{array}{c}\text { Adubação }+ \\
\text { calagem }\end{array}$ & $\begin{array}{c}\text { Adubação }+ \\
\text { hidrogel }\end{array}$ & $\begin{array}{c}\text { Adubação + } \\
\text { calagem + hidrogel }\end{array}$ & $\begin{array}{c}\text { C.V. } \\
\text { (\%) }\end{array}$ \\
\hline $\mathbf{N}$ & $26,8 \mathrm{a}$ & $24,7 \mathrm{a}$ & $25,7 \mathrm{a}$ & $25,5 \mathrm{a}$ & $26,6 \mathrm{a}$ & $26,8 \mathrm{a}$ & 14,9 \\
$\mathbf{P}$ & $5,7 \mathrm{ab}$ & $4,3 \mathrm{~b}$ & $5,5 \mathrm{ab}$ & $6,7 \mathrm{a}$ & $6,1 \mathrm{a}$ & $6,7 \mathrm{a}$ & 14,2 \\
$\mathbf{K}$ & $36,6 \mathrm{bc}$ & $22,7 \mathrm{c}$ & $57,5 \mathrm{a}$ & $39,3 \mathrm{~b}$ & $42,6 \mathrm{~b}$ & $40,9 \mathrm{~b}$ & 20,7 \\
$\mathbf{C a}$ & $8,5 \mathrm{a}$ & $8,7 \mathrm{a}$ & $8,8 \mathrm{a}$ & $9,1 \mathrm{a}$ & $8,9 \mathrm{a}$ & $9,0 \mathrm{a}$ & 20,1 \\
$\mathbf{M g}$ & $2,9 \mathrm{a}$ & $3,1 \mathrm{a}$ & $2,6 \mathrm{a}$ & $3,0 \mathrm{a}$ & $2,7 \mathrm{a}$ & $3,0 \mathrm{a}$ & 22,7 \\
\hline
\end{tabular}

C.V. = coeficiente de variação. Médias seguidas de mesma letra na linha não diferem entre si pelo teste Tukey a 5\%.

As menores concentrações de $\mathrm{P}$ nos tratamentos controle e hidrogel são justificáveis pela ausência de adubação e calagem, mantendo-se baixa a concentração deste elemento no solo. No entanto, o híbrido foi capaz de manter altas concentrações de P nos tecidos aéreos, demonstrando alta eficiência de uso do nutriente, com a conversão em biomassa de nutriente pouco disponível no solo. Cinco clones híbridos de eucalipto avaliados por Pinto et al. (2011) apresentaram alta eficiência de uso de fósforo, sendo menor apenas que o enxofre, demonstrando a facilidade de adaptação de materiais clonais às diversas condições edáficas.

Segundo Santana et al. (2008), mesmo os teores de nutrientes sendo baixos para os solos brasileiros, o eucalipto mantém bom desenvolvimento. Gonçalves et al. (2014) afirmam que a disponibilidade de P para Argissolos e Latossolos é um dos indicadores utilizados para avaliar o potencial do desenvolvimento do eucalipto em resposta à fertilização, pois teores de $\mathrm{P}$ entre $1-4 \mathrm{mg} \mathrm{dm}^{-3}$ são considerados de baixo a médio, porém, para a cultura do eucalipto, teores acima de $2 \mathrm{mg} \mathrm{dm}^{-3}$ já são suficientes para o desenvolvimento das árvores.

Os maiores teores de $\mathrm{K}$ na parte aérea ocorreram nos tratamentos em que houve fertilização, sendo significativamente maior $\left(57,5 \mathrm{~g} \mathrm{~kg}^{-1}\right)$ no tratamento adubação (Tabela 2). O aumento da concentração de $\mathrm{Ca}$ e $\mathrm{Mg}$ no solo, proporcionado pela calagem, possivelmente contribuiu para redução do $\mathrm{K}$ no solo e, consequentemente, menor absorção pelas plantas. Os cátions $\mathrm{Ca}^{2+}$ e $\mathrm{Mg}^{2+}$ são dominantes no complexo de troca do solo em comparação ao $\mathrm{K}^{+}$. Contudo, a absorção do $\mathrm{K}$ pelas plantas é favorecida dentre os cátions macronutrientes, que se apresenta, em geral, em menor concentração no solo e maior na planta (Oliveira et al., 2001).

O híbrido utilizado parece ter alta eficiência de absorção de K, devido à elevada concentração verificada nos tecidos aéreos. Esse também é um parâmetro desejável, já que os solos tropicais apresentam baixo conteúdo trocável de $\mathrm{K}$, textura arenosa, pouca matéria orgânica e baixa capacidade de troca catiônica, o que torna necessário o parcelamento da adubação potássica (Silveira \& Malavolta, 2000).

Rocha et al. (2014) consideram que apenas concentrações menores que $1,2 \mathrm{~g}^{\mathrm{de}} \mathrm{K} \mathrm{kg}^{-1}$ inibem o desenvolvimento do eucalipto. Contudo, níveis adequados nos tecidos promoverão maior qualidade e desenvolvimento das plantas. A adubação potássica em solos florestais é de extrema importância, já que o K está envolvido na ativação e síntese de proteínas, translocação, redução de nitratos, fotossíntese, regulação osmótica das células e síntese de metabólitos secundários que atuam na defesa das plantas (Mengel \& Kirkby, 2001).

Diferença significativa somente para os teores de K e P (Tabela 3) também foram observadas no solo. O tratamento adubação + hidrogel + calagem proporcionou maior teor de $\mathrm{K}$ no solo $\left(0,20 \mathrm{cmol}_{\mathrm{c}} \mathrm{dm}^{-3}\right)$ e o maior teor de $\mathrm{P}\left(3,12 \mathrm{cmol}_{\mathrm{c}} \mathrm{dm}^{-3}\right)$ foi obtido com o tratamento adubação + hidrogel, seguido de adubação e adubação + calagem, não diferindo entre si.

Para os demais nutrientes, a não detecção de diferenças pode estar relacionada à absorção pela planta. A disponibilidade dos nutrientes contidos no solo, ou a ele adicionados através das adubações, é bastante variável em função do $\mathrm{pH}$ do solo (Malavolta et al., 1997). Contudo, na cultura do eucalipto, o uso de calcário serve para fornecer $\mathrm{Ca}$ e $\mathrm{Mg}$, e não para neutralizar os excessos de A1 e Mn e corrigir a acidez do solo, pois as plantas toleram altos níveis desses elementos e são pouco sensíveis à acidez (Novais et al., 1990). 
Tabela 3. Atributos químicos do solo em função dos diferentes tratamentos, aos 240 dias após o transplante. Iguatemi, MS, 2014.

\begin{tabular}{|c|c|c|c|c|c|c|c|}
\hline \multirow{2}{*}{ Atributos } & \multicolumn{7}{|c|}{ Tratamentos } \\
\hline & Controle & Hidrogel & Adubação & $\mathbf{A}+\mathbf{C}$ & $\mathbf{A}+\mathbf{H}$ & $\mathbf{A}+\mathbf{C}+\mathbf{H}$ & CV $(\%)$ \\
\hline $\mathrm{pH}\left(\mathrm{CaCl}_{2}\right)$ & $4,35 \mathrm{a}$ & $4,24 \mathrm{a}$ & $4,44 \mathrm{a}$ & $4,43 \mathrm{a}$ & $4,38 \mathrm{a}$ & $4,41 \mathrm{a}$ & 3,5 \\
\hline $\mathrm{P}\left(\mathrm{mg} \mathrm{dm}^{-3}\right)$ & $1,68 \mathrm{~b}$ & $2,4 \mathrm{ab}$ & $2,84 \mathrm{a}$ & $2,22 \mathrm{ab}$ & $3,12 \mathrm{a}$ & $2,49 \mathrm{a}$ & 22,3 \\
\hline $\mathrm{K}\left(\mathrm{cmol}_{\mathrm{c}} \mathrm{dm}^{-3}\right)$ & $0,05 \mathrm{~b}$ & $0,14 \mathrm{a}$ & $0,15 \mathrm{a}$ & $0,16 \mathrm{a}$ & $0,18 \mathrm{a}$ & $0,20 \mathrm{a}$ & 23,4 \\
\hline $\mathrm{Ca}\left(\mathrm{cmol}_{\mathrm{c}} \mathrm{dm}^{-3}\right)$ & $0,39 \mathrm{a}$ & $0,31 \mathrm{a}$ & $0,31 \mathrm{a}$ & $0,34 \mathrm{a}$ & $0,35 \mathrm{a}$ & $0,42 \mathrm{a}$ & 17,3 \\
\hline $\operatorname{Mg}\left(\mathrm{cmol}_{\mathrm{c}} \mathrm{dm}^{-3}\right)$ & $0,24 \mathrm{a}$ & $0,23 \mathrm{a}$ & $0,23 \mathrm{a}$ & $0,21 \mathrm{a}$ & $0,26 \mathrm{a}$ & $0,27 \mathrm{a}$ & 29,3 \\
\hline $\mathrm{SB}\left(\mathrm{cmol}_{\mathrm{c}} \mathrm{dm}^{-3}\right)$ & $0,68 \mathrm{a}$ & $0,71 \mathrm{a}$ & $0,89 \mathrm{a}$ & $0,69 \mathrm{a}$ & $0,70 \mathrm{a}$ & $0,89 \mathrm{a}$ & 17,9 \\
\hline $\mathrm{Al}\left(\mathrm{cmol}_{\mathrm{c}} \mathrm{dm}^{-3}\right)$ & $0,24 \mathrm{a}$ & $0,32 \mathrm{a}$ & $0,34 \mathrm{a}$ & $0,28 \mathrm{a}$ & $0,20 \mathrm{a}$ & $0,2 \mathrm{a}$ & 36,8 \\
\hline $\mathrm{H}+\mathrm{Al}\left(\mathrm{cmol}_{\mathrm{c}} \mathrm{dm}^{-3}\right)$ & $3,46 \mathrm{a}$ & $3,60 \mathrm{a}$ & $3,55 \mathrm{a}$ & $3,10 \mathrm{a}$ & $3,46 \mathrm{a}$ & $3,37 \mathrm{a}$ & 8,4 \\
\hline $\mathrm{CTC}\left(\mathrm{cmol}_{\mathrm{c}} \mathrm{dm}^{-3}\right)$ & $4,15 \mathrm{a}$ & $4,30 \mathrm{a}$ & $4,25 \mathrm{a}$ & $3,79 \mathrm{a}$ & $4,25 \mathrm{a}$ & $4,25 \mathrm{a}$ & 7,2 \\
\hline V (\%) & $16,51 \mathrm{a}$ & $16,30 \mathrm{a}$ & $16,41 \mathrm{a}$ & $18,14 \mathrm{a}$ & $18,74 \mathrm{a}$ & $20,83 \mathrm{a}$ & 17,6 \\
\hline $\mathrm{Cu}\left(\mathrm{mg} \mathrm{kg}^{-1}\right)$ & $0,75 \mathrm{a}$ & $0,72 \mathrm{a}$ & $0,69 \mathrm{a}$ & $0,60 \mathrm{a}$ & $0,71 \mathrm{a}$ & $0,67 \mathrm{a}$ & 19,5 \\
\hline $\operatorname{Mn}\left(\mathrm{mg} \mathrm{kg}^{-1}\right)$ & $56,66 \mathrm{a}$ & $52,09 \mathrm{a}$ & $51,79 \mathrm{a}$ & $46,38 \mathrm{a}$ & $61,09 \mathrm{a}$ & $46,06 \mathrm{a}$ & 18,9 \\
\hline $\mathrm{Fe}\left(\mathrm{mg} \mathrm{kg}^{-1}\right)$ & 150,86 a & $144,45 \mathrm{a}$ & $129,44 \mathrm{a}$ & $119,35 \mathrm{a}$ & $127,60 \mathrm{a}$ & $113,71 \mathrm{a}$ & 22,1 \\
\hline $\mathrm{Zn}\left(\mathrm{mg} \mathrm{kg}^{-1}\right)$ & $0,81 \mathrm{a}$ & $0,75 \mathrm{a}$ & $0,59 \mathrm{a}$ & $0,78 \mathrm{a}$ & $0,79 \mathrm{a}$ & $0,69 \mathrm{a}$ & 20,1 \\
\hline
\end{tabular}

$\mathrm{SB}, \mathrm{H}^{+}+\mathrm{Al}^{3+}$, CTC, V são, respectivamente, soma de bases, potencial hidrogeniônico, acidez potencial, capacidade de troca catiônica e índice de saturação por bases. $\mathrm{A}+\mathrm{C}=$ adubação + calagem; $\mathrm{A}+\mathrm{H}=$ adubação + hidrogel e $\mathrm{A}+\mathrm{C}+\mathrm{H}=$ adubação + calagem + hidrogel. Médias seguidas de mesma letra na linha não diferem entre si pelo teste Tukey a $5 \%$.

As concentrações de Al e $\mathrm{H}+\mathrm{Al}$ (Tabela 3) apresentaram-se acima do esperado, pois em geral a calagem reduz esses atributos químicos do solo, assim como foi observado por Montanari et al. (2008), que verificaram a neutralização do $\mathrm{Al}(0,1$ $\left.\mathrm{cmol}_{\mathrm{c}} \mathrm{dm}^{-3}\right)$ e redução de $\mathrm{H}+\mathrm{Al}\left(2,1 \mathrm{cmol}_{\mathrm{c}} \mathrm{dm}^{-3}\right) \mathrm{com}$ o uso da calagem em um Latossolo.

Para os micronutrientes, não foi observada diferença significativa entre os tratamentos (Tabela 3 ).

\section{Conclusões}

O uso do hidrogel isoladamente não favorece o crescimento das plantas, contudo aumenta a sobrevivência quando comparado ao tratamento controle, sem hidrogel ou adubação adicional.

No solo, o hidrogel foi capaz de aumentar a disponibilidade de $\mathrm{P}$ e $\mathrm{K}$ quando comparado ao tratamento controle. Quando associado à adubação, o hidrogel intensificou o crescimento, promovendo maior altura e diâmetro do caule, bem como a elevação dos teores de $\mathrm{P}$ e $\mathrm{K}$ na parte aérea.

Os resultados indicam viabilidade do emprego de hidrogel em Argissolo. Porém, mais estudos devem ser realizados para comprovação de seus efeitos e recomendação de dosagens adequadas quando associado à adubação.

\section{Referências}

Anuário estatístico da ABRAF 2013: ano base 2012. Brasília, DF, 2013. 148 p. Disponível em: <http://www.bibliotecaflorestal.ufv.br/ handle/123456789/3910>. Acesso em: 22 set. 2014.

Bernardi, M. R. et al. Crescimento em mudas de Corymbia citriodora em função do uso de hidrogel e adubação. Cerne, v. 18, n. 1, p. $67-$ 74, 2012. DOI: 10.1590/S0104-77602012000100009.

Costa, T. G. et al. Qualidade da madeira de cinco espécies de ocorrência no cerrado para produção de carvão vegetal. Cerne, v. 20, n. 1, p. 37-46, 2014. DOI: 10.1590/S0104-77602014000100005.

Gonçalves, J. L. et al. Nutrição e adubação da cultura do eucalipto manejada no sistema de talhadia. In: Prado, R. M. \& Wadt, P. G. S. (Ed.). Nutrição e adubação de espécies florestais e palmeiras. Jaboticabal: FCAV/CAPES, 2014. p. 349-382.

Gonçalves, J. L. Recomendações de adubação para Eucalyptus, Pinus e espécies típicas da Mata atlântica. Piracicaba: ESALQ, 1995. 23 p. (Documentos florestais, 15).

Köppen, W. Climatologia: con un estudio de los climas de la tierra. México: Fondo de Cultura Económica, 1948. 478 p.

Lopes, J. L. W. et al. Uso de hidrogel na sobrevivência de mudas de Eucalyptus urograndis produzidas com diferentes substratos e manejos hídricos. Ciência Florestal, v. 20, n. 2, p. 217-224, 2010. DOI: 10.5902/198050981847.

Malavolta, E. et al. Avaliação do estado nutricional das plantas: princípios e aplicações. Piracicaba: POTAFOS, 1997. 319 p.

Mengel, K. \& Kirkby, E. Principles of plant nutrition. 5. ed. Dordrecht: Kluwer Academic Publishers, 2001. 849 p. 
Montanari, R. et al. Variabilidade espacial de atributos químicos em Latossolo e Argissolo. Ciência Rural, v. 38, p. 1266-1272, 2008. DOI: $10.1590 / \mathrm{S} 0103-84782008000500010$.

Novais, R. F. et al. Nutrição mineral do eucalipto. In: Barros. N. F.; Novais, R. E. (Ed.). Relação solo-eucalipto. Viçosa, MG Folha de Viçosa, 1990. 330 p.

Oliveira, F. A. et al. Disponibilidade de potássio e suas relações com cálcio e magnésio em soja cultivada em casa-de-vegetação. Scientia Agricola, v. 58, n. 2, p. 329-335, 2001. DOI: 10.1590/ S0103-90162001000200016.

Pinto, S. I. C. et al. Eficiência nutricional de clones de eucalipto na fase de mudas cultivados em solução nutritiva. Revista Brasileira de Ciência do Solo, v. 35, p. 523-533, 2011. DOI: 10.1590/S010006832011000200021 .

Raij, B. V. et al. Análise química para avaliação da fertilidade de solos tropicais. Campinas: Instituto Agronômico, 2001. 285 p.

Rocha, S. A. et al. Crescimento e nutrição foliar de mudas de Eucalyptus sp. irrigados com diferentes qualidades de água. Revista de Ciências Agrárias. Recife, v. 37, n. 2, p. 141-151. 2014.

Santana, R. C. et al. Alocação de nutrientes em plantios de eucalipto no Brasil. Revista Brasileira de Ciência do Solo, v. 32, n. especial. p. 2723-2733, 2008. DOI: 10.1590/S0100-06832008000700016.
Santos, H. G. dos et al. Sistema brasileiro de classificação de solos. 3. ed. Brasília, DF: Embrapa, 2013. 353 p.

Silva, C. A. et al. Interação calagem-adubação fosfatada e sua influência nos níveis críticos de P e crescimento do eucalipto. Scientia Forestalis, v. 1, n. 73, p. 63-72, 2007.

Silveira, R. L. A. \& Malavolta, E. Nutrição e adubação potássica em Eucaluptus. Informações Agronômicas, n. 91, p. 1-12, 2000. Encarte técnico.

Souza, C. R. et al. Comportamento da Acacia mangium e de clones de Eucalyptus grandis x E. urophylla em plantios experimentais na Amazônia Central. Scientia Forestalis, v. 65, p. 95-101, 2004.

Souza, N. H. et al. Crescimento inicial de Stryphnodendron polyphylum (Mart.) em resposta à adubação com N e P. Cerne, v. 20, n. 3, p. 441-447. 2014. DOI: 10.1590/01047760201420031425.

Tonini, H. et al. Avaliação de espécies florestais em área de mata no estado de Roraima. Cerne, v. 12, n. 1, p. 8-18, 2006.

Vezzani, F. M. et al. Alterações dos nutrientes no solo e nas plantas em consórcio de eucalipto e acácia negra. Revista Brasileira de Ciência do Solo, v. 25, p. 225-231, 2001. DOI: 10.1590/S010006832001000100024. 
